\title{
Inflammatory Cytokines in Diabetic Nephropathy
}

\author{
Javier Donate-Correa, ${ }^{1}$ Ernesto Martín-Núñez, ${ }^{1}$ Mercedes Muros-de-Fuentes, ${ }^{2}$ \\ Carmen Mora-Fernández, ${ }^{1}$ and Juan F. Navarro-González ${ }^{1,3}$ \\ ${ }^{1}$ Research Unit, University Hospital Nuestra Señora de Candelaria, 38010 Santa Cruz de Tenerife, Spain
${ }^{2}$ Clinical Biochemistry Service, University Hospital Nuestra Señora de Candelaria, 38010 Santa Cruz de Tenerife, Spain
${ }^{3}$ Nephrology Service, University Hospital Nuestra Señora de Candelaria, 38010 Santa Cruz de Tenerife, Spain
}

Correspondence should be addressed to Javier Donate-Correa; jdonate@ull.es

and Juan F. Navarro-González; jnavgon@gobiernodecanarias.org

Received 28 November 2014; Revised 17 January 2015; Accepted 31 January 2015

Academic Editor: Ronald G. Tilton

Copyright (C) 2015 Javier Donate-Correa et al. This is an open access article distributed under the Creative Commons Attribution License, which permits unrestricted use, distribution, and reproduction in any medium, provided the original work is properly cited.

Probably, the most paradigmatic example of diabetic complication is diabetic nephropathy, which is the largest single cause of end-stage renal disease and a medical catastrophe of worldwide dimensions. Metabolic and hemodynamic alterations have been considered as the classical factors involved in the development of renal injury in patients with diabetes mellitus. However, the exact pathogenic mechanisms and the molecular events of diabetic nephropathy remain incompletely understood. Nowadays, there are convincing data that relate the diabetes inflammatory component with the development of renal disease. This review is focused on the inflammatory processes that develop diabetic nephropathy and on the new therapeutic approaches with anti-inflammatory effects for the treatment of chronic kidney disease in the setting of diabetic nephropathy.

\section{Introduction}

Diabetes-related complications represent one of the most important health problems worldwide with dire projections. One of the most important medical concerns of the diabetes epidemic is diabetic nephropathy (DN). Approximately onethird of all diabetic patients are affected by DN [1], which produces significant social and economic burdens [2] and constitutes the most frequent cause of end-stage renal disease (ESRD) $[3,4]$. In addition, renal involvement is a major cause of morbidity and mortality in the diabetic population, with this epidemic being likely to drive us to previously unforeseen rates of vascular target organ complications.

The concept of the underlying pathophysiologic processes leading to DN has evolved tremendously. In the classical view, renal injury in these patients is explained by metabolic and hemodynamic alterations, which increase systemic and intraglomerular pressure, and by the modification of molecules under hyperglycemic conditions. This view has evolved to a much more complex scenario, where the pathogenesis of DN appears as multifactorial, with both genetic and environmental factors triggering a complex series of pathophysiological events $[5,6]$. Intensive research in recent years on the aetiology of DN at the cellular and molecular level has given rise to inflammation as a key pathophysiological mechanism. Understanding the key features of inflammatory mechanisms involved in the development and progression of diabetic kidney injury will enable the identification of new potential targets and facilitate the design of innovative antiinflammatory therapeutic strategies.

This review is focused on the pathogenesis of DN associated with the inflammatory process. We focus on proinflammatory molecules and pathways related to the development and progression of renal injury, discuss the potential clinical use of inflammatory markers as predictors of $\mathrm{DN}$, and comment upon potential new strategies to treat DN using agents that target inflammatory pathways.

\section{Inflammation}

There now are convincing data that diabetes includes an inflammatory component that is thought to be related to diabetic complications. Our understanding of the role of this 
component is still restricted to specific molecules and single pathways, so our understanding of the highly complex and diverse molecular interactions that occur in the kidneys of patients with $\mathrm{DN}$ is very superficial.

Diabetes mellitus is associated with a myriad of deviations from normal homeostasis which includes hemodynamic abnormalities (resulting from systemic and intraglomerular hypertension, altered shear stress, and mechanical strain), metabolic derangements (hyperglycemia, formation of advanced glycation end products, and hyperlipidemia), and increased synthesis of hormones such as angiotensin II. Additionally, an increasing number of studies suggest that oxidative stress, inflammation, and fibrosis appear to be the key links in the progression of DN. Oxidative stress is the initial part of DN and activates a variety of pathological pathways in virtually all types of kidney cells (endothelial, mesangial, epithelial, tubular cells, and podocytes). However, fibrosis is the most fundamental and prominent feature of DN and inflammation appears to be the central role [7] in the onset and progression of kidney fibrosis if uncontrolled.

Plasma concentrations of inflammatory molecules, including proinflammatory cytokines, are elevated in diabetic patients [8-10]. Recent studies have shown that concentrations of these substances increase as nephropathy progresses $[11,12]$ and that these inflammatory molecules are independently related to urinary albumin excretion (UAE) $[12,13]$ presenting a direct association with clinical markers of glomerular and tubulointerstitial damage. The extent of inflammatory cell accumulation in the kidney is closely associated with DN [14-18]. Indeed, inhibition of inflammatory cell recruitment into the kidney has been shown to be protective in experimental diabetic nephropathy $[19,20]$. Together, these results suggest that inflammation may be a pathogenic factor for the development and progression of DN [21]. Proinflammatory and fibrogenic cytokines synthesized and secreted by these cells in the local microenvironment directly damage kidney architecture and subsequently trigger the epithelial-to-mesenchymal transition process [22], resulting in extracellular matrix accumulation. Not only the synthesis of proinflammatory cytokines, but also the expression of chemoattractant cytokines and adhesion molecules are upregulated in animal and patients kidney cells with diabetes. These molecules are key mediators of renal injury by virtue of their ability to attract circulating white blood cells (monocytes, neutrophils, and lymphocytes) and facilitate transmigration of these cells into renal tissue. These infiltrating cells are also a source of cytokines and other mediators that contribute to the development and progression of renal injury, as well as to amplification and perpetuation of the inflammatory reaction.

Immunologic and inflammatory mechanisms play a significant role in development and progression of DN [23, 24] with recruitment and activation of innate immune cells and elaboration of proinflammatory cytokines. Thereby, macrophages and T-lymphocytes, which are prominent in diabetic glomeruli $[25,26]$, as well as different molecules, such as chemokines [27, 28], adhesion molecules [20, 29], growth factors [30-33], nuclear factors [34, 35], and cytokines
[21], have been implicated in diverse pathogenic pathways related to $\mathrm{DN}$.

\section{Inflammatory Cytokines in the Pathophysiology of Diabetic Nephropathy}

Cytokines are a group of pharmacologically active, low molecular weight polypeptides with autocrine, paracrine, and juxtacrine effects which, in a coordinated manner, regulate inflammatory and immune responses with the participation of different cytokine-associated signalling pathways. Cytokines are produced throughout the body by cells of varied embryological origin and, in addition to their immune response regulatory role, exert important pleiotropic actions as cardinal effectors of injury [36]. At present time, it is recognized that chronic low-grade inflammation and activation of the innate immune system are closely involved in the pathogenesis of diabetes mellitus [37-39]. Plasma concentrations of diverse inflammatory parameters are elevated in diabetic patients [8-10, 40, 41] being strong predictors of the development of this disease [42-44].

A potential participation of inflammatory cytokines in the pathogenesis of DN was suggested for the first time in 1991 by Hasegawa et al. [45]. In this work, authors demonstrated that peritoneal macrophages cultured with glomerular basement membranes from diabetic rats produced significantly higher amounts of the inflammatory cytokines tumor necrosis factor-alpha (TNF- $\alpha$ ) and interleukin- (IL-) 1 than those cultured with glomerular basement membranes from normal rats. Subsequent studies demonstrated that, in the kidney, both blood-borne cells (mainly monocytes and macrophages) and diverse intrinsic renal cells (endothelial, mesangial, dendritic, and tubular epithelial cells) are able to synthesize inflammatory cytokines [46-50]. Furthermore, the levels of these substances increase as nephropathy progresses $[11,12,48]$, with an independent relationship between inflammatory parameters and urinary albumin excretion (UAE) $[12,13]$ suggesting a role of this substances in the pathogenesis of DN $[13,49,50]$.

Inflammatory cytokines involved in the pathogenesis of diabetes play a significant role in the development and progression of several renal disorders [51], including DN [13, 45, 50]. The renal effects of inflammatory cytokines are related to the expression of different molecules, intraglomerular hemodynamic abnormalities, alteration of extracellular matrix, and glomerular basement membranes, apoptosis and necrosis, endothelial permeability, oxidative stress, and so forth [21, 52-57], determining the development of microvascular diabetic complications, including neuropathy, retinopathy, and nephropathy [24, 49, 58-61].

Serum and urinary levels of interleukin- (IL-) 18 have been reported to be higher in patients with $\mathrm{DN}$ than in control subjects, showing significant positive correlations with UAE rate in DN patients [62-64]. IL-18 is a potent proinflammatory cytokine implicated in different actions, including the release of interferon- (IFN-) $\gamma$ [65], which stimulates functional chemokine receptor expression in 
human mesangial cells [66], the synthesis of other molecules involved in the inflammatory reaction, such as IL-1 and TNF$\alpha$, the increase in the expression of ICAM-1, and the apoptotic process of endothelial cells [67-69]. Tubular renal cells show an increase in the expression of IL-18 in patients with DN [70], which has been related to the triggering of mitogenactivated protein kinase (MAPK) pathways secondary to the action of TGF- $\beta$ [71]. Many other cells may also produce this cytokine, such as infiltrating monocytes, macrophages, and $\mathrm{T}$ cells $[72,73]$.

Renal cells (endothelial, epithelial, mesangial, and tubular cells) are also capable of synthesizing proinflammatory cytokines such as TNF- $\alpha$, IL-1, and IL-6, and, therefore, these cytokines, acting in a paracrine or autocrine manner, may induce a variety of effects on different renal structures $[51,74,75]$ playing a significant role in the development and progression of several renal disorders [51].

TNF- $\alpha$ is mainly produced by monocytes, macrophages, and T cells but also intrinsic kidney cells $[46,76,77]$. Many clinical studies in patients with DN have reported that the serum and urinary concentrations of TNF- $\alpha$ are elevated as compared with nondiabetic individuals or with diabetic subjects and kidneys and that these concentrations increase concomitantly with the progression of DN. These findings indicate a potential relationship between the elevated levels of this inflammatory cytokine and the development and progression of renal injury in DM $[13,62,78]$. Experimental studies in animal models of diabetes have showed that TNF- $\alpha$ protein and expression levels are enhanced in renal glomeruli and tubules $[46,79-81]$. TNF- $\alpha$ may cause direct cytotoxicity to renal cells, inducing direct renal injury [82], apoptosis, and necrotic cell death $[83,84]$. It can also produce alterations of intraglomerular blood flow and reduction of glomerular filtration as consequence of the disequilibrium between factors promoting vasoconstriction and vasodilation [85], in addition to changes in the permeability of endothelial cells. In addition, TNF- $\alpha$ is able to directly induce the formation of ROS by renal cells [56]. Experimental researches have shown that TNF- $\alpha$ induces the activation of NADPH oxidase in isolated rat glomeruli through the activation of the intracellular pathways protein kinase C/phosphatidylinositol-3 kinase and MAPK [56]. Thus, TNF- $\alpha$ prompts local ROS production, independent of hemodynamic mechanisms, resulting in alterations of the glomerular capillary wall and consequently increased albumin permeability [86].

Kidney hypertrophy and hyperfiltration are early and relevant findings of $\mathrm{DN}$, and both are significantly related to TNF- $\alpha[81,87]$. In vitro studies demonstrated that TNF$\alpha$ stimulates the solute uptake in proximal tubular cells secondary to the activation of sodium-dependent cotransporters [88], whereas in vivo studies in diabetic rats found an enhanced urinary excretion of TNF- $\alpha$ excretion, which was related to sodium retention and renal hypertrophy. All these effects could be blocked by the use of a soluble TNF$\alpha$ receptor fusion protein $[81,88]$. In the renal distal tubule TNF- $\alpha$ activates the epithelial sodium channel resulting in an increased reabsorption of sodium, which can be abrogated by blockers of this renal channel, such as amiloride, and inhibitors of extracellular signal related protein kinase.
The increment in renal sodium reabsorption might induce the expression of TFG- $\beta$, with the development of renal hypertrophy [89].

Similarly to TNF- $\alpha$, IL-6 levels are also higher in patients with DN in comparison with diabetes mellitus patients without nephropathy [90]. In addition, the histopathological analysis of human renal samples by immunohistochemistry has demonstrated an increased expression of mRNA encoding IL-6 in cells infiltrating the mesangium, interstitium, and tubules, with a positive relationship with the severity of mesangial expansion [91]. Other functional and structural abnormalities related to DN and progression of renal damage have been associated with IL-6, including abnormalities in the permeability of glomerular endothelium, expansion of mesangial cells and enhanced expression of fibronectin [54], and increase in the thickness of the GBM $[92,93]$. Our experimental studies have demonstrated an increase in the mRNA levels of IL-6 in the renal cortex of diabetic rats, which is positively associated with the urinary concentration of this cytokine [79]. In addition, in animal models of diabetes, wet kidney weight, a marker of renal hypertrophy and an early phenomenon in kidney involvement in DM, has been reported to be enhanced, which was related to mRNA gene expression levels and urine concentration of this cytokine [79].

\section{New Therapies Targeting Inflammation}

Nowadays, there are no available treatments to prevent the development of DN. Main therapeutic strategies are based on strict control of mayor modifiable risks like hypertension, glucose levels, and dyslipidemia but do not always prevent the ultimate progression of DN [94]. Therefore, the identification of therapies that specifically target $\mathrm{DN}$ by affecting the primary mechanisms that contribute to the pathogenesis could be useful and really needed in addition to risk factors control [95].

Inflammation process underlays the mechanisms of DN progression. Therefore, anti-inflammatory strategies may offer approaches of great interest in these patients. Several currently used treatments associated with renoprotective effects are postulated to be at least partly related to antiinflammatory actions. The renin-angiotensin-aldosterone system (RAAS) is a major pathway involved in the pathogenesis and progression of DN [96]. Therapeutic RAAS blockade is achieved by two ways: by using angiotensinconverting enzyme (ACE) inhibitors or angiotensin II receptor (AR) blockers. Both are effective strategies that reduce proteinuria and slow progression of diabetic and nondiabetic nephropathy by hemodynamic/antihypertensive and by antiinflammatory/antifibrotic actions. The second action is mediated by the reduction in angiotensin II (AngII) levels, which activates nuclear factor (NF- $\kappa \mathrm{B})$ and interacts with transforming growth factor- $\beta$ (TGF- $\beta$ ). The anti-inflammatory action occurs via inhibition of NF- $\kappa \mathrm{B}$-dependent pathways [97].

Although the RAAS blockade provides pleiotropic, antiinflammatory actions potentially relevant in the therapeutic approach to this complication [98-101], new therapeutic 
agents with potential effects upon primary mechanisms are on the horizon. One of these alternatives could be based on the use of pentoxifylline (PTF) which possesses significant anti-inflammatory properties. PTF is a methylxanthinederived phosphodiesterase inhibitor with beneficial effects on microcirculatory blood flow due to its rheological properties. PTF is employed in the use of intermittent claudication resulting from peripheral vascular disease. In patients with DM, PTF therapy has been associated with a reduction in UAE and with potential beneficial effects on GFR [102106]. Recent studies have shown that PTF reduces urinary protein excretion in diabetic subjects, both with normal renal function $[107,108]$ and with renal insufficiency [106]. Interestingly, this antiproteinuric effect has been related to a reduction in the concentrations of TNF- $\alpha$, one of the most important proinflammatory cytokines [106, 109]. This antiproteinuric action has been confirmed in various prospective, controlled, randomised clinical studies [108, $110,111]$. The drug inhibits TNF- $\alpha$ gene transcription and blocks TNF- $\alpha$ mRNA accumulation $[100,112]$ significantly reducing TNF- $\alpha$ levels and urinary protein excretion without metabolic or haemodynamic changes [106-108], even in patients under blockade of the RAS with Ang II receptor antagonists [109]. These studies showed a significant association between the reduction in proteinuria and the decrease in TNF- $\alpha$ activity $[106,109]$. In addition, PTF has a considerable capacity to modulate other proinflammatory cytokines and molecules, including IFN- $\gamma$, IL-10, and IL-6, as well as to attenuate cellular processes involved in the inflammatory response (activation, adhesion, and phagocytosis) without metabolic or haemodynamic changes [113-115]. A metaanalysis published in 2008 which focused on the use of PTF in patients with $\mathrm{DN}$ found a substantial reduction in urinary protein excretion and pointed to the capacity of PTF to reduce the production of proinflammatory cytokines as the most likely explanation for this antiproteinuric action [116]. Therefore, PTF could represent a therapeutic approximation to the anti-inflammatory treatment of DN.

One in vitro study has showed that PTF decreased cellular production of fibronectin and TGF- $\beta$ induced by high glucose concentrations in cultured human mesangial cells and exerted protective effects against angiotensin-II-induced actions on matrix proteins [117]. Recent experimental studies in animal diabetic models show that administration of PTF prevents an increase in renal expression, synthesis, and excretion of TNF- $\alpha$, IL-1, and IL-6, which was directly and significantly associated with a reduction in renal sodium retention, renal hypertrophy, and urinary albumin excretion $[79,109]$.

An independent, prospective, randomized, controlled, clinical trial investigating the potential renoprotective effect of PTF administration in patients with DN, under standard care with RAS blockers, recently reported a slowing of the rate of progression of nephropathy among patients with type 2 diabetes [118] with a smaller decrease in eGFR and a higher reduction of residual UAE compared with control group nontreated with PTF. Patients showed a reduction in urinary TNF- $\alpha$ after PTF administration, which was directly correlated with the change in UAE and inversely correlated with the variation in the eGFR. No significant relationship was observed between serum and urinary levels of this cytokine, indicating that TNF- $\alpha$ is produced within the kidneys and that PTF administration is associated with a modulation in its production and urinary excretion.

Further convincing evidence is, however, needed before pentoxifylline can be considered a real option for the treatment of DN. Therefore, PTF should not be considered part of clinical practice without more definitive trials (largescale, adequately powered, multicenter, prospective, placebocontrolled studies, with definitive endpoints on efficacy and safety) to demonstrate with the maximum grade of evidence the renoprotective, anti-inflammatory properties of PTF in this population.

\section{Conclusions}

Providing diabetic patients with protection from the development and progression of renal injury remains a challenge for nephrologists. In this context, the need to identify new therapeutic targets and additional strategies for treating DN is clearly evident, especially since current treatments do not completely stop the development and progression of renal injury in the diabetic patient. Diabetic nephropathy is considered an inflammatory disease, and several reports recently demonstrated inflammasome activation in association with diabetic nephropathy [119]. The modulation of inflammatory processes might be useful in the prevention or therapy of DN. Inflammatory cytokines exert an important diversity of actions implicated in this disease, from development to the initial stages of diabetes to progression and to late stages of renal failure. The recognition of these molecules as significant pathogenic factors and the development of new techniques for examining changes in the expression of pathogenic genes involved in inflammatory pathways in this complication will provide new therapeutic targets.

From a therapeutic perspective, limited experience is available regarding the inhibition of inflammatory cytokines in DN. Mounting evidence implies beneficial properties of ACE inhibitors beyond those of their original effects. Therefore, modulation of inflammatory phenomena by blocking the RAS in DN is of great interest. Diverse in vitro and in vivo studies have shown that ACE inhibitors have inhibitory effects on proinflammatory cytokine expression and synthesis $[79,120-124]$ which are not related to the antihypertensive effects of these drugs [125]. Therapies with ACE inhibitors in patients with congestive heart failure or advanced chronic renal disease have demonstrated that is associated with a significant decrease in TNF- $\alpha$ and IL-6 activity [126, 127]. Based on these findings, it is possible to hypothesize that other angiotensin-dependent processes, such as those related to proinflammatory cytokine regulation, play a significant role in the development and progression of $\mathrm{DN}$, and, therefore, blockade of cytokine-mediated inflammatory activity may have important effects on the renoprotective benefit associated with RAS blockade.

To date, diverse studies have shown that PTF administration is able to reduce the main proinflammatory cytokines related to a decrease in renal hypertrophy and UAE. These 
beneficial effects are independent of any improvement in metabolic or haemodynamic parameters [79]. However, further clinical trials are necessary to examine the potential renoprotective efficacy of PTF and other anti-inflammatory cytokines in establishing remission or even regression of DN.

\section{Disclosure}

Javier Donate-Correa, Mercedes Muros de Fuentes, Carmen Mora-Fernández, and Juan F. Navarro-González are members of the GEENDIAB (Spanish Group for the Study of Diabetic Nephropathy, RETIC/REDinREN/RD12/0021/0019, ISCIII). Juan F. Navarro-González is national coordinator of GEENDIAB. Research activity by Juan F. Navarro-González is supported by Programa de Intensificación de la Actividad Investigadora (ISCIII/Comunidad Autónoma de Canarias).

\section{Conflict of Interests}

The authors declare that there is no conflict of interests regarding the publication of this paper.

\section{References}

[1] R. C. Atkins and P. Zimmet, "Diabetic kidney disease: act now or pay later," Kidney International, vol. 77, no. 5, pp. 375-377, 2010.

[2] M. E. Cooper, "Diabetes: treating diabetic nephropathy-still an unresolved issue," Nature Reviews Endocrinology, vol. 8, no. 9, pp. 515-516, 2012.

[3] E. Ritz, I. Rychlik, F. Locatelli, and S. Halimi, "End-stage renal failure in type 2 diabetes: a medical catastrophe of worldwide dimensions," American Journal of Kidney Diseases, vol. 34, no. 5, pp. 795-808, 1999.

[4] R. C. Atkins, "The epidemiology of chronic kidney disease," Kidney International, Supplement, vol. 67, no. 94, pp. S14-S18, 2005.

[5] G. Wolf, "New insights into the pathophysiology of diabetic nephrophathy: from haemodynamics to molecular pathology," European Journal of Clinical Investigation, vol. 34, no. 12, pp. 785-796, 2004.

[6] S. Martini, F. Eichinger, V. Nair, and M. Kretzler, "Defining human diabetic nephropathy on the molecular level: integration of transcriptomic profiles with biological knowledge," Reviews in Endocrine and Metabolic Disorders, vol. 9, no. 4, pp. 267-274, 2008.

[7] J. Wada and H. Makino, "Inflammation and the pathogenesis of diabetic nephropathy," Clinical Science, vol. 124, no. 3, pp. 139152, 2013.

[8] J. C. Pickup, M. B. Mattock, G. D. Chusney, and D. Burt, "NIDDM as a disease of the innate immune system: association of acute-phase reactants and interleukin-6 with metabolic syndrome X," Diabetologia, vol. 40, no. 11, pp. 1286-1292, 1997.

[9] A. Katsuki, Y. Sumida, S. Murashima et al., "Serum levels of tumor necrosis factor- $\alpha$ are increased in obese patients with noninsulin-dependent diabetes mellitus," Journal of Clinical Endocrinology and Metabolism, vol. 83, no. 3, pp. 859-862, 1998.

[10] J. C. Pickup, G. D. Chusney, S. M. Thomas, and D. Burt, "Plasma interleukin-6, tumour necrosis factor $\alpha$ and blood cytokine production in type 2 diabetes," Life Sciences, vol. 67, no. 3, pp. 291-300, 2000.

[11] G. Bruno, F. Merletti, A. Biggeri et al., "Progression to overt nephropathy in type 2 diabetes: the Casale Monferrato study," Diabetes Care, vol. 26, no. 7, pp. 2150-2155, 2003.

[12] A. Festa, R. D’Agostino, G. Howard, L. Mykkänen, R. P. Tracy, and S. M. Haffner, "Inflammation and microalbuminuria in nondiabetic and type 2 diabetic subjects: the Insulin Resistance Atherosclerosis Study," Kidney International, vol. 58, no. 4, pp. 1703-1710, 2000.

[13] J. F. Navarro, C. Mora, M. Macía, and J. García, "Inflammatory parameters are independently associated with urinary albumin in type 2 diabetes mellitus," The American Journal of Kidney Diseases, vol. 42, no. 1, pp. 53-61, 2003.

[14] F. Chow, E. Ozols, D. J. Nikolic-Paterson, R. C. Atkins, and G. $\mathrm{H}$. Tesch, "Macrophages in mouse type 2 diabetic nephropathy: correlation with diabetic state and progressive renal injury," Kidney International, vol. 65, no. 1, pp. 116-128, 2004.

[15] D. Nguyen, F. Ping, W. Mu, P. Hill, R. C. Atkins, and S. J. Chadban, "Macrophage accumulation in human progressive diabetic nephropathy," Nephrology, vol. 11, no. 3, pp. 226-231, 2006.

[16] A. K. H. Lim, F. Y. Ma, D. J. Nikolic-Paterson, A. R. Kitching, M. C. Thomas, and G. H. Tesch, "Lymphocytes promote albuminuria, but not renal dysfunction or histological damage in a mouse model of diabetic renal injury," Diabetologia, vol. 53, no. 8, pp. 1772-1782, 2010.

[17] R. Moriya, J. C. Manivel, and M. Mauer, "Juxtaglomerular apparatus T-cell infiltration affects glomerular structure in Type 1 diabetic patients," Diabetologia, vol. 47, no. 1, pp. 82-88, 2004.

[18] D. Ferenbach, D. C. Kluth, and J. Hughes, "Inflammatory cells in renal injury and repair," Seminars in Nephrology, vol. 27, no. 3, pp. 250-259, 2007.

[19] A. S. Awad, G. R. Kinsey, K. Khutsishvili, T. Gao, W. K. Bolton, and M. D. Okusa, "Monocyte/macrophage chemokine receptor CCR2 mediates diabetic renal injury," The American Journal of Physiology-Renal Physiology, vol. 301, no. 6, pp. F1358-F1366, 2011.

[20] F. Y. Chow, D. J. Nikolic-Paterson, E. Ozols, R. C. Atkins, and G. H. Tesch, "Intercellular adhesion molecule-1 deficiency is protective against nephropathy in type 2 diabetic $\mathrm{db} / \mathrm{db}$ mice," Journal of the American Society of Nephrology, vol. 16, no. 6, pp. 1711-1722, 2005.

[21] J. F. Navarro-González and C. Mora-Fernández, "The role of inflammatory cytokines in diabetic nephropathy," Journal of the American Society of Nephrology, vol. 19, no. 3, pp. 433-442, 2008.

[22] Y. Liu, "Cellular and molecular mechanisms of renal fibrosis," Nature Reviews Nephrology, vol. 7, no. 12, pp. 684-696, 2011.

[23] K. R. Tuttle, "Linking metabolism and immunology: diabetic nephropathy is an inflammatory disease," Journal of the American Society of Nephrology, vol. 16, no. 6, pp. 1537-1538, 2005.

[24] C. Mora and J. F. Navarro, "Inflammation and diabetic nephropathy," Current Diabetes Reports, vol. 6, no. 6, pp. 463$468,2006$.

[25] E. Galkina and K. Ley, "Leukocyte recruitment and vascular injury in diabetic nephropathy," Journal of the American Society of Nephrology, vol. 17, no. 2, pp. 368-377, 2006.

[26] K.-I. Shikata and H. Makino, "Role of macrophages in the pathogenesis of diabetic nephropathy," Contributions to Nephrology, vol. 134, pp. 46-54, 2001. 
[27] C.-G. Ihm, "Monocyte chemotactic peptide-1 in diabetic nephropathy," Kidney International, vol. 52, supplement 60, pp. S20S22, 1997.

[28] F. Y. Chow, D. J. Nikolic-Paterson, E. Ozols, R. C. Atkins, B. J. Rollin, and G. H. Tesch, "Monocyte chemoattractant protein-1 promotes the development of diabetic renal injury in streptozotocin-treated mice," Kidney International, vol. 69, no. 1, pp. 73-80, 2006.

[29] S. Okada, K. Shikata, M. Matsuda et al., "Intercellular adhesion molecule-1-deficient mice are resistant against renal injury after induction of diabetes," Diabetes, vol. 52, no. 10, pp. 2586-2593, 2003.

[30] T. Nakagawa, "Uncoupling of the VEGF-endothelial nitric oxide axis in diabetic nephropathy: an explanation for the paradoxical effects of VEGF in renal disease," The American Journal of Physiology-Renal Physiology, vol. 292, no. 6, pp. 1665-1672, 2007.

[31] A. Flyvbjerg, D. S. Khatir, L. J. N. Jensen, F. Dagnæs-Hansen, H. Gronbaek, and R. Rasch, "The involvement of growth hormone (GH), insulin-like growth factor (IGFs) and vascular endothelial growth factor (VEGF) in diabetic kidney disease," Current Pharmaceutical Design, vol. 10, no. 27, pp. 3385-3394, 2004.

[32] T. Pantsulaia, "Role of TGF-beta in pathogenesis of diabetic nephropathy," Georgian Medical News, no. 131, pp. 13-18, 2006.

[33] F. P. Schena and L. Gesualdo, "Pathogenetic mechanisms of diabetic nephropathy," Journal of the American Society of Nephrology, vol. 16, no. 3, supplement 1, pp. S30-S33, 2005.

[34] S. Mezzano, C. Aros, A. Droguett et al., "NF-kappaB activation and overexpression of regulated genes in human diabetic nephropathy," Nephrology Dialysis Transplantation, vol. 19, no. 10, pp. 2505-2512, 2004.

[35] H. Schmid, A. Boucherot, Y. Yasuda et al., "Modular activation of nuclear factor- $\kappa \mathrm{B}$ transcriptional programs in human diabetic nephropathy," Diabetes, vol. 55, no. 11, pp. 2993-3003, 2006.

[36] W. Aldhahi and O. Hamdy, "Adipokines, inflammation, and the endothelium in diabetes," Current Diabetes Reports, vol. 3, no. 4, pp. 293-298, 2003.

[37] J. C. Pickup and M. A. Crook, "Is type II diabetes mellitus a disease of the innate immune system?" Diabetologia, vol. 41, no. 10, pp. 1241-1248, 1998.

[38] M. Crook, "Type 2 diabetes mellitus: a disease of the innate immune system? An update," Diabetic Medicine, vol. 21, no. 3, pp. 203-207, 2004.

[39] J. C. Pickup, "Inflammation and activated innate immunity in the pathogenesis of type 2 diabetes," Diabetes Care, vol. 27, no. 3, pp. 813-823, 2004.

[40] J.-W. Chen, M.-A. Gall, H. Yokoyama, J. S. Jensen, M. Deckert, and H.-H. Parving, "Raised serum sialic acid concentration in NIDDM patients with and without diabetic nephropathy," Diabetes Care, vol. 19, no. 2, pp. 130-134, 1996.

[41] M. Rodríguez-Morán and F. Guerrero-Romero, "Increased levels of C-reactive protein in noncontrolled type II diabetic subjects," Journal of Diabetes and Its Complications, vol. 13, no. 4, pp. 211-215, 1999.

[42] M. I. Schmidt, B. B. Duncan, A. R. Sharrett et al., "Markers of inflammation and prediction of diabetes mellitus in adults (Atherosclerosis Risk in Communities study): a cohort study," The Lancet, vol. 353, no. 9165, pp. 1649-1652, 1999.
[43] A. D. Pradhan, J. E. Manson, N. Rifai, J. E. Buring, and P. M. Ridker, "C-reactive protein, interleukin 6, and risk of developing type 2 diabetes mellitus," The Journal of the American Medical Association, vol. 286, no. 3, pp. 327-334, 2001.

[44] J. Spranger, A. Kroke, M. Möhlig et al., "Inflammatory cytokines and the risk to develop type 2 diabetes: results of the prospective population-based European Prospective Investigation into Cancer and Nutrition (EPIC)-Potsdam Study," Diabetes, vol. 52, no. 3, pp. 812-817, 2003.

[45] G. Hasegawa, K. Nakano, M. Sawada et al., "Possible role of tumor necrosis factor and interleukin-1 in the development of diabetic nephropathy," Kidney International, vol. 40, no. 6, pp. 1007-1012, 1991.

[46] H. Sugimoto, K. Shikata, J. Wada, S. Horiuchi, and H. Makino, "Advanced glycation end products-cytokine-nitric oxide sequence pathway in the development of diabetic nephropathy: aminoguanidine ameliorates the overexpression of tumour necrosis factor- $\alpha$ and inducible nitric oxide synthase in diabetic rat glomeruli," Diabetologia, vol. 42 , no. 7 , pp. $878-$ 886, 1999.

[47] L. Baud, B. Fouqueray, C. Philippe, and A. Amrani, "Tumor necrosis factor alpha and mesangial cells," Kidney International, vol. 41, no. 3, pp. 600-603, 1992.

[48] J. Egido, M. Gómez-Chiarri, A. Ortíz et al., "Role of tumor necrosis factor-alpha in the pathogenesis of glomerular diseases," Kidney International, Supplement, vol. 43, supplement 39, pp. S59-S64, 1993.

[49] J. F. Navarro and C. Mora, "Role of inflammation in diabetic complications," Nephrology Dialysis Transplantation, vol. 20, no. 12, pp. 2601-2604, 2005.

[50] C. Mora, J. F. Navarro, Y. Moriwaki, and T. Yamamoto, "Inflammation and pathogenesis of diabetic nephropathy," Metabolism: Clinical and Experimental, vol. 53, no. 2, pp. 265-267, 2004.

[51] I. L. Noronha, Z. Niemir, H. Stein, and R. Waldherr, "Cytokines and growth factors in renal disease," Nephrology Dialysis Transplantation, vol. 10, no. 6, pp. 775-786, 1995.

[52] J. Pfeilschifter, W. Pignat, K. Vosbeck, and F. Marki, "Interleukin 1 and tumor necrosis factor synergistically stimulate prostaglandin synthesis and phospholipase A2 release from rat renal mesangial cells," Biochemical and Biophysical Research Communications, vol. 159, no. 2, pp. 385-394, 1989.

[53] J. Pfeilschifter and H. Mühl, "Interleukin-1 and tumor necrosis factor potentiate angiotensin II- and calcium ionophorestimulated prostaglandin E2 synthesis in rat renal mesangial cells," Biochemical and Biophysical Research Communications, vol. 169, no. 2, pp. 585-595, 1990.

[54] D. L. Coleman and C. Ruef, "Interleukin-6: an autocrine regulator of mesangial cell growth," Kidney International, vol. 41, no. 3, pp. 604-606, 1992.

[55] S. Jones and A. O. Phillips, "Regulation of renal proximal tubular epithelial cell hyaluronan generation: implications for diabetic nephropathy," Kidney International, vol. 59, no. 5, pp. 1739-1749, 2001.

[56] N. Koike, T. Takamura, and S. Kaneko, "Induction of reactive oxygen species from isolated rat glomeruli by protein kinase $\mathrm{C}$ activation and TNF- $\alpha$ stimulation, and effects of a phosphodiesterase inhibitor," Life Sciences, vol. 80, no. 18, pp. 1721-1728, 2007.

[57] E. T. Mccarthy, R. Sharma, M. Sharma et al., "TNF- $\alpha$ increases albumin permeability of isolated rat glomeruli through the generation of superoxide," Journal of the American Society of Nephrology, vol. 9, no. 3, pp. 433-438, 1998. 
[58] D. S. Skundric and R. P. Lisak, "Role of neuropoietic cytokines in development and progression of diabetic polyneuropathy: from glucose metabolism to neurodegeneration," Experimental Diabesity Research, vol. 4, no. 4, pp. 303-312, 2003.

[59] W. J. Jeffcoate, F. Game, and P. R. Cavanagh, "The role of proinflammatory cytokines in the cause of neuropathic osteoarthropathy (acute Charcot foot) in diabetes," The Lancet, vol. 366, no. 9502, pp. 2058-2061, 2005.

[60] N. Demircan, B. G. Safran, M. Soylu, A. A. Ozcan, and S. Sizmaz, "Determination of vitreous interleukin-1 (IL-1) and tumour necrosis factor (TNF) levels in proliferative diabetic retinopathy," Eye, vol. 20, no. 12, pp. 1366-1369, 2006.

[61] M. C. Mocan, S. Kadayifcilar, and B. Eldem, "Elevated intravitreal interleukin-6 levels in patients with proliferative diabetic retinopathy," Canadian Journal of Ophthalmology, vol. 41, no. 6, pp. 747-752, 2006.

[62] Y. Moriwaki, T. Yamamoto, Y. Shibutani et al., "Elevated levels of interleukin-18 and tumor necrosis factor-alpha in serum of patients with type 2 diabetes mellitus: relationship with diabetic nephropathy," Metabolism: Clinical and Experimental, vol. 52, no. 5, pp. 605-608, 2003.

[63] A. Nakamura, K. Shikata, M. Hiramatsu et al., "Serum interleukin-18 levels are associated with nephropathy and atherosclerosis in Japanese patients with type 2 diabetes," Diabetes Care, vol. 28, no. 12, pp. 2890-2895, 2005.

[64] C. K. Wong, A. W. Y. Ho, P. C. Y. Tong et al., "Aberrant activation profile of cytokines and mitogen-activated protein kinases in type 2 diabetic patients with nephropathy," Clinical \& Experimental Immunology, vol. 149, no. 1, pp. 123-131, 2007.

[65] H. Okamura, H. Tsutsui, T. Komatsu et al., "Cloning of a new cytokine that induces IFN-gamma production by T cells," Nature, vol. 378, no. 6552, pp. 88-91, 1995.

[66] M. Schwarz, M. Wahl, K. Resch, and H. H. Radeke, "IFN $\gamma$ induces functional chemokine receptor expression in human mesangial cells," Clinical \& Experimental Immunology, vol. 128, no. 2, pp. 285-294, 2002.

[67] S.-M. Dai, H. Matsuno, H. Nakamura, K. Nishioka, and K. Yudoh, "Interleukin-18 enhances monocyte tumor necrosis factor $\alpha$ and interleukin- $1 \beta$ production induced by direct contact with T lymphocytes: implications in rheumatoid arthritis," Arthritis and Rheumatism, vol. 50, no. 2, pp. 432-443, 2004.

[68] E. Mariño and J. E. Cardier, "Differential effect of IL-18 on endothelial cell apoptosis mediated by TNF-alpha and Fas (CD95)," Cytokine, vol. 22, no. 5, pp. 142-148, 2003.

[69] R. J. L. Stuyt, M. G. Netea, T. B. H. Geijtenbeek, B. J. Kullberg, C. A. Dinarello, and J. W. M. van der Meer, "Selective regulation of intercellular adhesion molecule-1 expression by interleukin18 and interleukin-12 on human monocytes," Immunology, vol. 110, no. 3, pp. 329-334, 2003.

[70] G. Fantuzzi, D. A. Reed, and C. A. Dinarello, "IL-12-induced IFNgamma is dependent on caspase-1 processing of the IL-18 precursor," The Journal of Clinical Investigation, vol. 104, no. 6, pp. 761-767, 1999.

[71] K. Miyauchi, Y. Takiyama, J. Honjyo, M. Tateno, and M. Haneda, "Upregulated IL-18 expression in type 2 diabetic subjects with nephropathy: TGF-betal enhanced IL-18 expression in human renal proximal tubular epithelial cells," Diabetes Research and Clinical Practice, vol. 83, no. 2, pp. 190-199, 2009.

[72] V. Y. Melnikov, T. Ecder, G. Fantuzzi et al., "Impaired IL18 processing protects caspase-1-deficient mice from ischemic acute renal failure," The Journal of Clinical Investigation, vol. 107, no. 9, pp. 1145-1152, 2001.
[73] V. Y. Melnikov, S. Faubel, B. Siegmund, M. S. Lucia, D. Ljubanovic, and C. L. Edelstein, "Neutrophil-independent mechanisms of caspase-1- and IL-18-mediated ischemic acute tubular necrosis in mice," The Journal of Clinical Investigation, vol. 110, no. 8, pp. 1083-1091, 2002.

[74] F. Mariano, B. Bussolati, G. Piccoli, and G. Camussi, "Renal vascular effects of cytokines," Blood Purification, vol. 15, no. 4-6, pp. 262-272, 1997.

[75] T. Ostendorf, M. Burg, and J. Floege, "Cytokines and glomerular injury," Kidney and Blood Pressure Research, vol. 19, no. 5, pp. 281-289, 1996.

[76] A. M. Jevnikar, D. C. Brennan, G. G. Singer et al., "Stimulated kidney tubular epithelial cells express membrane associated and secreted TNF $\alpha$," Kidney International, vol. 40, no. 2, pp. 203-211, 1991.

[77] X. Dong, S. Swaminathan, L. A. Bachman, A. J. Croatt, K. A. Nath, and M. D. Griffin, "Resident dendritic cells are the predominant TNF-secreting cell in early renal ischemiareperfusion injury," Kidney International, vol. 71, no. 7, pp. 619628, 2007.

[78] J. F. Navarro, C. Mora, M. Muros, and J. García, "Urinary tumour necrosis factor-alpha excretion independently correlates with clinical markers of glomerular and tubulointerstitial injury in type 2 diabetic patients," Nephrology Dialysis Transplantation, vol. 21, no. 12, pp. 3428-3434, 2006.

[79] J. F. Navarro, F. J. Milena, C. Mora, C. León, and J. García, "Renal pro-inflammatory cytokine gene expression in diabetic nephropathy: effect of angiotensin-converting enzyme inhibition and pentoxifylline administration," The American Journal of Nephrology, vol. 26, no. 6, pp. 562-570, 2007.

[80] J. F. Navarro, F. J. Milena, C. Mora et al., “Tumor necrosis factoralpha gene expression in diabetic nephropathy: relationship with urinary albumin excretion and effect of angiotensinconverting enzyme inhibition," Kidney International, Supplement, no. 99, pp. S98-S102, 2005.

[81] K. Dipetrillo and F. A. Gesek, "Pentoxifylline ameliorates renal tumor necrosis factor expression, sodium retention, and renal hypertrophy in diabetic rats," The American Journal of Nephrology, vol. 24, no. 3, pp. 352-359, 2004.

[82] T. Bertani, M. Abbate, C. Zoja et al., "Tumor necrosis factor induces glomerular damage in the rabbit," The American Journal of Pathology, vol. 134, no. 2, pp. 419-430, 1989.

[83] S. M. Laster, J. G. Wood, and L. R. Gooding, "Tumor necrosis factor can induce both apoptic and necrotic forms of cell lysis," Journal of Immunology, vol. 141, no. 8, pp. 2629-2634, 1988.

[84] J. J. Boyle, P. L. Weissberg, and M. R. Bennett, "Tumor necrosis factor- $\alpha$ promotes macrophage-induced vascular smooth muscle cell apoptosis by direct and autocrine mechanisms," Arteriosclerosis, Thrombosis, and Vascular Biology, vol. 23, no. 9, pp. 1553-1558, 2003.

[85] L. Baud, J. Perez, G. Friedlander, and R. Ardaillou, “Tumor necrosis factor stimulates prostaglandin production and cyclic AMP levels in rat cultured mesangial cells," FEBS Letters, vol. 239, no. 1, pp. 50-54, 1988.

[86] E. T. Mccarthy, R. Sharma, M. Sharma et al., "TNF- $\alpha$ increases albumin permeability of isolated rat glomeruli through the generation of superoxide," Journal of the American Society of Nephrology, vol. 9, no. 3, pp. 433-438, 1998.

[87] K. DiPetrillo, B. Coutermarsh, and F. A. Gesek, "Urinary tumor necrosis factor contributes to sodium retention and renal hypertrophy during diabetes," The American Journal of 
Physiology-Renal Physiology, vol. 284, no. 1, pp. F113-F121, 2003.

[88] G. F. Schreiner and D. E. Kohan, "Regulation of renal transport processes and hemodynamics by macrophages and lymphocytes," The American Journal of Physiology-Renal Fluid and Electrolyte Physiology, vol. 258, no. 4, pp. F761-F767, 1990.

[89] H. C. M. Yu, L. M. Burrell, M. J. Black et al., "Salt induces myocardial and renal fibrosis in normotensive and hypertensive rats," Circulation, vol. 98, no. 23, pp. 2621-2628, 1998.

[90] P. Mahadevan, R. G. Larkins, J. R. E. Fraser, A. J. Fosang, and M. E. Dunlop, "Increased hyaluronan production in the glomeruli from diabetic rats: a link between glucose-induced prostaglandin production and reduced sulphated proteoglycan," Diabetologia, vol. 38, no. 3, pp. 298-305, 1995.

[91] D. Suzuki, M. Miyazaki, R. Naka et al., "In situ hybridization of interleukin 6 in diabetic nephropathy," Diabetes, vol. 44, no. 10, pp. 1233-1238, 1995.

[92] R. Nosadini, M. Velussi, E. Brocco et al., "Course of renal function in type 2 diabetic patients with abnormalities of albumin excretion rate," Diabetes, vol. 49, no. 3, pp. 476-484, 2000.

[93] M. Dalla Vestra, M. Mussap, P. Gallina et al., "Acute-phase markers of inflammation and glomerular structure in patients with type 2 diabetes," The Journal of the American Society of Nephrology, vol. 16, supplement 1, pp. S78-S82, 2005.

[94] T. H. Hostetter, "Prevention of end-stage renal disease due to type 2 diabetes," The New England Journal of Medicine, vol. 345, no. 12, pp. 910-912, 2001.

[95] M. E. Williams and K. R. Tuttle, "The next generation of diabetic nephropathy therapies: an update," Advances in Chronic Kidney Disease, vol. 12, no. 2, pp. 212-222, 2005.

[96] P. Ruggenenti, P. Cravedi, and G. Remuzzi, “The RAAS in the pathogenesis and treatment of diabetic nephropathy," Nature Reviews, vol. 6, no. 6, pp. 319-330, 2010.

[97] F. T. H. Lee, Z. Cao, D. M. Long et al., "Interactions between angiotensin II and NF- $\kappa$ B-dependent pathways in modulating macrophage infiltration in experimental diabetic nephropathy," The Journal of the American Society of Nephrology, vol. 15, no. 8, pp. 2139-2151, 2004.

[98] N. J. Dagenais and F. Jamali, "Protective effects of angiotensin II interruption: evidence for antiinflammatory actions," Pharmacotherapy, vol. 25, no. 9, pp. 1213-1229, 2005.

[99] P. Dandona, S. Dhindsa, H. Ghanim, and A. Chaudhuri, "Angiotensin II and inflammation: the effect of angiotensinconverting enzyme inhibition and angiotensin II receptor blockade," Journal of Human Hypertension, vol. 21, no. 1, pp. 2027, 2007.

[100] J. Han, P. Thompson, and B. Beutler, "Dexamethasone and pentoxifylline inhibit endotoxin-induced cachectin/tumor necrosis factor synthesis at separate points in the signaling pathway," The Journal of Experimental Medicine, vol. 172, no. 1, pp. 393-394, 1990.

[101] K. Takebayashi, S. Matsumoto, Y. Aso, and T. Inukai, "Aldosterone blockade attenuates urinary monocyte chemoattractant protein-1 and oxidative stress in patients with type 2 diabetes complicated by diabetic nephropathy," The Journal of Clinical Endocrinology \& Metabolism, vol. 91, no. 6, pp. 2214-2217, 2006.

[102] S. B. Solerte, M. Fioravanti, A. Bozzetti et al., "Pentoxifylline, albumin excretion rate and proteinuria in type I and type II diabetic patients with microproteinuria. Results of a short-term randomized study," Acta Diabetologia Latina, vol. 23, no. 2, pp. 171-177, 1986.
[103] K. Tripathi, J. Prakash, D. Appaiha, and P. K. Srivastava, "Pentoxifylline in management of proteinuria in diabetic nephropathy," Nephron, vol. 64, no. 4, pp. 641-642, 1993.

[104] D. M. Gorson, "Reduction of macroalbuminuria with pentoxifylline in diabetic nephropathy. Report of three cases," Diabetes Care, vol. 21, no. 12, pp. 2190-2191, 1998.

[105] J. F. Navarro, C. Mora, A. Rivero et al., "Urinary protein excretion and serum tumor necrosis factor in diabetic patients with advanced renal failure: effects of pentoxifylline administration," The American Journal of Kidney Diseases, vol. 33, no. 3, pp. 458463, 1999.

[106] J. E. Navarro, C. Mora, and D. M. Gorson, "Antiproteinuric effect of pentoxifylline in patients with diabetic nephropathy," Diabetes Care, vol. 22, no. 6, pp. 1006-1008, 1999.

[107] F. Guerrero-Romero, M. Rodriguez-Moran, J. R. PaniaguaSierra, G. Garcia-Bulnes, M. Salas-Ramirez, and D. Amato, "Pentoxifylline reduces proteinuria in insulin-dependent and non insulin-dependent diabetic patients," Clinical Nephrology, vol. 43, no. 2, pp. 116-121, 1995.

[108] J. F. Navarro, C. Mora, M. Muros, M. Macía, and J. García, "Effects of pentoxifylline administration on urinary $N$-acetyl$\beta$-glucosaminidase excretion in type 2 diabetic patients: a shortterm, prospective, randomized study," American Journal of Kidney Diseases, vol. 42, no. 2, pp. 264-270, 2003.

[109] J. F. Navarro, C. Mora, M. Muros, and J. García, "Additive antiproteinuric effect of pentoxifylline in patients with type 2 diabetes under angiotensin II receptor blockade: a shortterm, randomized, controlled trial," The Journal of the American Society of Nephrology, vol. 16, no. 7, pp. 2119-2126, 2005.

[110] M. Rodríguez-Morán, G. González-González, M. V. BermúdezBarba et al., "Effects of pentoxifylline on the urinary protein excretion profile of type 2 diabetic patients with microproteinuria: a double-blind, placebo-controlled randomized trial," Clinical Nephrology, vol. 66, no. 1, pp. 3-10, 2006.

[111] R. Leyva-Jiménez, A. R. Rodríguez-Orozco, L. E. OrtegaPierres, J. Ramírez-Enríquez, A. Gómez-García, and C. AlvarezAguilar, "Effect of pentoxifylline on the evolution of diabetic nephropathy," Medicina Clinica, vol. 132, no. 20, pp. 772-778, 2009.

[112] G. M. Doherty, J. C. Jensen, H. R. Alexander, C. M. Buresh, and J. A. Norton, "Pentoxifylline suppression of tumor necrosis factor gene transcription," Surgery, vol. 110, no. 2, pp. 192-198, 1991.

[113] L. Voisin, D. Breuillé, B. Ruot et al., "Cytokine modulation by PX differently affects specific acute phase proteins during sepsis in rats," The American Journal of Physiology-Regulatory Integrative and Comparative Physiology, vol. 275, no. 5, pp. R1412-R1419, 1998.

[114] L. Tissi, M. Puliti, R. Barluzzi, G. Orefici, C. Von Hunolstein, and F. Bistoni, "Role of tumor necrosis factor alpha, interleukin$1 \beta$, and interleukin- 6 in a mouse model of group B streptococcal arthritis," Infection and Immunity, vol. 67, no. 9, pp. 4545-4550, 1999.

[115] A. Cooper, A. Mikhail, M. W. Lethbridge, D. M. Kemeny, and I. C. Macdougall, "Pentoxifylline improves hemoglobin levels in patients with erythropoietin-resistant anemia in renal failure," Journal of the American Society of Nephrology, vol. 15, no. 7, pp. 1877-1882, 2004.

[116] B. B. McCormick, A. Sydor, A. Akbari, D. Fergusson, S. Doucette, and G. Knoll, "The effect of pentoxifylline on proteinuria in diabetic kidney disease: a meta-analysis," American Journal of Kidney Diseases, vol. 52, no. 3, pp. 454-463, 2008. 
[117] D. T. Bolick, M. E. Hatley, S. Srinivasan, C. C. Hedrick, and J. L. Nadler, "Lisofylline, a novel antiinflammatory compound, protects mesangial cells from hyperglycemia- and angiotensin II-mediated extracellular matrix deposition," Endocrinology, vol. 144, no. 12, pp. 5227-5231, 2003.

[118] J. F. Navarro-González, C. Mora-Fernández, M. Muros de Fuentes et al., "Effect of pentoxifylline on renal function and urinary albumin excretion in patients with diabetic kidney disease: the PREDIAN trial," Journal of the American Society of Nephrology, vol. 26, no. 1, pp. 220-229, 2014.

[119] K. Shahzad, F. Bock, W. Dong et al., "Nlrp3-inflammasome activation in non-myeloid-derived cells aggravates diabetic nephropathy,' Kidney International, vol. 87, no. 1, pp. 74-84, 2015.

[120] T. Moriyama, M. Fujibayashi, Y. Funjiwara et al., "Angiotensin II stimulates interleukin-6 release from cultured mouse mesangial cells," Journal of the American Society of Nephrology, vol. 6, no. 1, pp. 95-101, 1995.

[121] A. C. Peeters, M. G. Netea, B. J. Kullberg, T. Thien, and J. W. M. van der Meer, "The effect of renin-angiotensin system inhibitors on pro- and anti- inflammatory cytokine production," Immunology, vol. 94, no. 3, pp. 376-379, 1998.

[122] E. Lindmark and A. Siegbahn, "Tissue factor regulation and cytokine expression in monocyte-endothelial cell co-cultures: effects of a statin, an ACE-inhibitor and a low-molecular-weight heparin," Thrombosis Research, vol. 108, no. 1, pp. 77-84, 2002.

[123] L. A. Ortiz, H. C. Champion, J. A. Lasky et al., "Enalapril protects mice from pulmonary hypertension by inhibiting TNF-mediated activation of NF- $\kappa \mathrm{B}$ and AP-1," The American Journal of Physiology - Lung Cellular and Molecular Physiology, vol. 282, no. 6, pp. L1209-L1221, 2002.

[124] H. Kaneto, J. J. Morrissey, R. Mccracken, S. Ishidoya, A. A. Reyes, and S. Klahr, "The expression of mRNA for tumour necrosis factor- $\alpha$ increases in the obstructed kidney of rats soon after unilateral ureteral ligation," Nephrology, vol. 2, no. 3, pp. 161-166, 1996.

[125] R. Schindler, C. A. Dinarello, and K.-M. Koch, "Angiotensinconverting-enzyme inhibitors suppress synthesis of tumour necrosis factor and interleukin 1 by human peripheral blood mononuclear cells," Cytokine, vol. 7, no. 6, pp. 526-533, 1995.

[126] L. Gullestad, P. Aukrust, T. Ueland et al., "Effect of highversus low-dose angiotensin converting enzyme inhibition on cytokine levels in chronic heart failure," Journal of the American College of Cardiology, vol. 34, no. 7, pp. 2061-2067, 1999.

[127] P. Stenvinkel, P. Andersson, T. Wang et al., "Do ACE-inhibitors suppress tumour necrosis factor- $\alpha$ production in advanced chronic renal failure?" Journal of Internal Medicine, vol. 246, no. 5, pp. 503-507, 1999. 


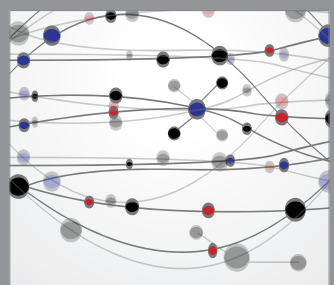

The Scientific World Journal
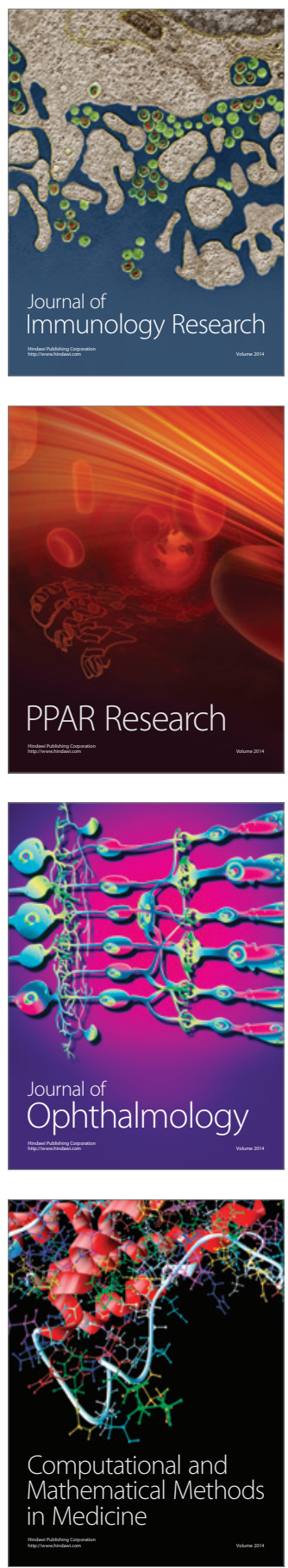

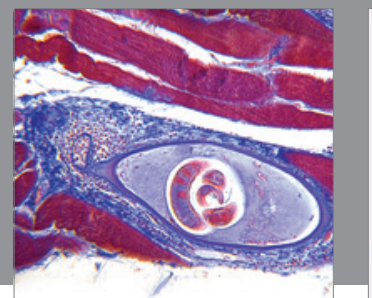

Gastroenterology

Research and Practice
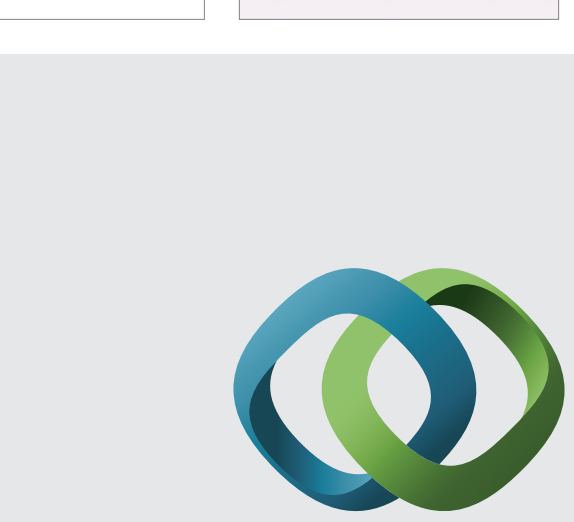

\section{Hindawi}

Submit your manuscripts at

http://www.hindawi.com
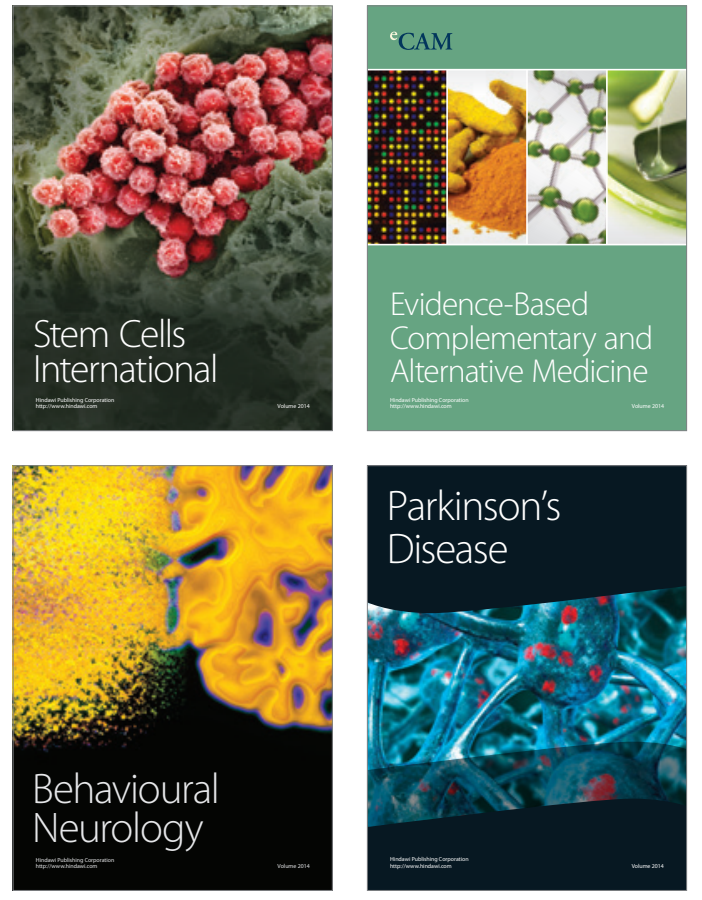
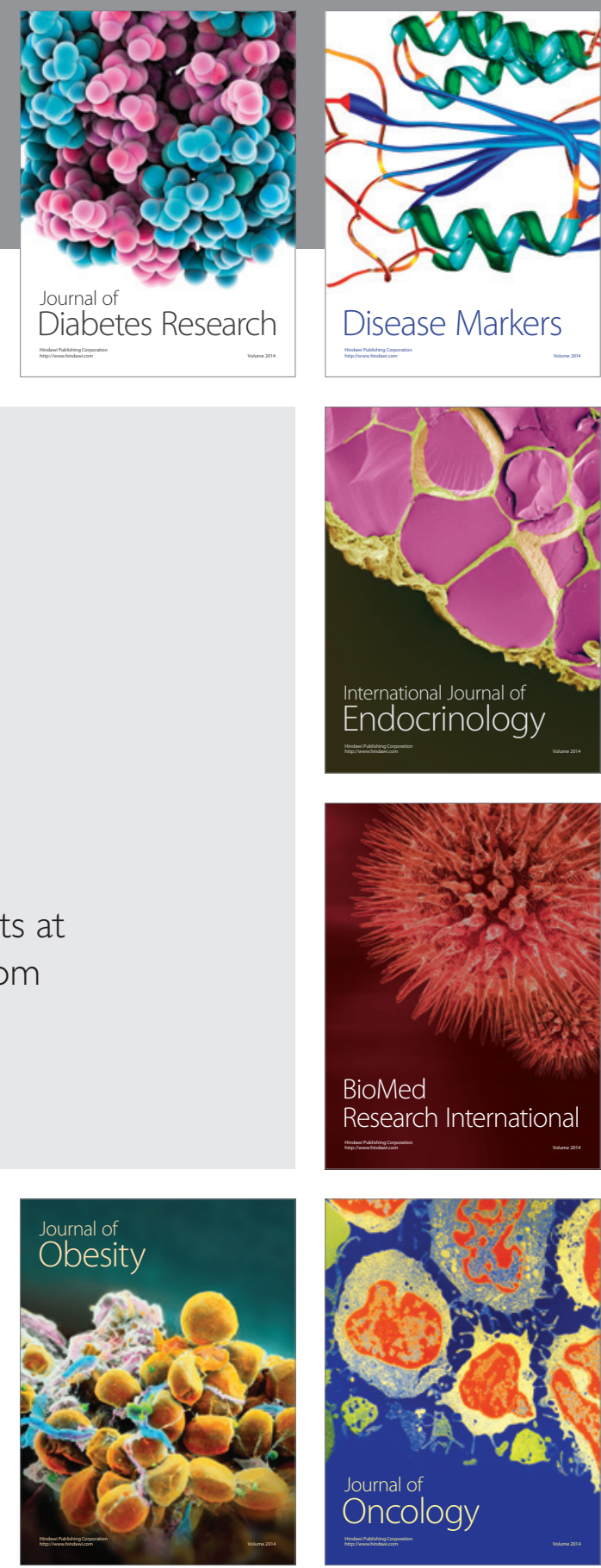

Disease Markers
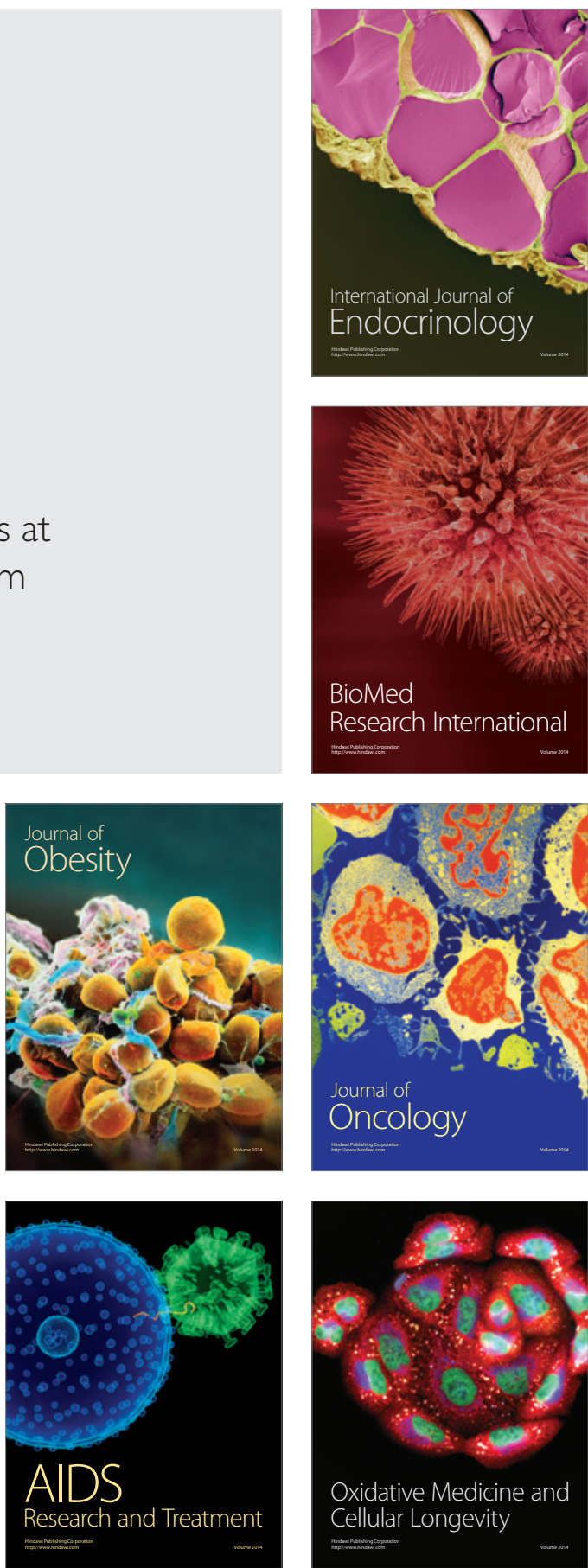